\title{
Protective effects of SIRT1 in patients with proliferative diabetic retinopathy via the inhibition of IL-17 expression
}

\author{
SHULIN LIU ${ }^{1,2^{*}}$, YU LIN $^{3 *}$ and XIN LIU ${ }^{4}$ \\ ${ }^{1}$ Chongqing Key Laboratory of Ophthalmology; ${ }^{2}$ Chongqing Eye Institute, Department of Ophthalmology, \\ The First Affiliated Hospital of Chongqing Medical University; ${ }^{3}$ Department of Traditional Chinese Medicine; \\ ${ }^{4}$ Department of Pharmacy, Chongqing Medical University, Chongqing 400016, P.R. China
}

Received May 12, 2015; Accepted November 5, 2015

DOI: $10.3892 /$ etm.2015.2877

\begin{abstract}
Diabetic retinopathy (DR) is a chronic microvascular complication of diabetes that may lead to loss of vision. The pathogenesis of DR is complex and elevated expression levels of $\mathrm{T}$ helper (Th)17 cells and interleukin (IL)-17 have been suggested to be associated with the development and progression of DR. Sirtuin 1 (SIRT1) is a nicotinamide-adenine dinucleotide ${ }^{+}$-dependent histone deacetylase that is downregulated in patients with DR. Previous studies have demonstrated that SIRT1 is capable of inhibiting the production of IL-17. In the present study, 19 patients with proliferative diabetic retinopathy (PDR) and 20 non-diabetic controls with idiopathic macular epiretinal membranes were recruited and the SIRT1 expression levels of excised specimens were analyzed using immunohistochemistry. IL-17 expression levels in the sera from patients with PDR and controls were determined by enzyme-linked immunosorbent assay (ELISA). Furthermore, SIRT1 mRNA and protein expression levels in peripheral blood mononuclear cells (PBMCs) from the two groups were analyzed following culture with or without a SIRT1 activator, resveratrol. IL-17 expression levels in the supernatants of PBMCs were determined using ELISA and the results demonstrated that IL-17 expression levels were increased in the sera of patients with PDR, as compared with the controls. Furthermore, increased expression levels of SIRT1 and IL-17 were detected in fibrovascular membranes and PBMCs harvested from patients with PDR, respectively. Notably, SIRT1 mRNA and protein expression levels were decreased in the PBMCs of patients with PDR and IL-17 production was inhibited following SIRT1 activation. The results of the present study
\end{abstract}

Correspondence to: Professor Xin Liu, Department of Pharmacy, Chongqing Medical University, 1 Yi Xue Yuan Road, Yu Zhong, Chongqing 400016, P.R. China

E-mail: liuxin8829@sina.com

*Contributed equally

Key words: sirtuin, interleukin-17, resveratrol, proliferative diabetic retinopathy, epiretinal membrane indicated that imbalanced IL-17 and SIRT1 expression levels may contribute to the pathogenesis of DR, and SIRT1 may have a protective role in PDR by inhibiting the production of IL-17.

\section{Introduction}

Diabetic retinopathy (DR) is a sight-threatening, chronic microvascular complication of diabetes. DR, which accounts for $5 \%$ of all blindness, affects $\sim 5$ million patients worldwide and is characterized by the progressive occlusion of capillaries, leading to retinal nonperfusion and ischemia (1). In an ischemic retina, the induction of vascular endothelial growth factor (VEGF) expression mediates the pathological intraocular proliferation of vessels which characterizes proliferative diabetic retinopathy (PDR) (2). The majority of diabetic patients develop varying degrees of retinopathy by 20 years of disease duration (3). In 2012, there were 93 million cases of DR globally, 17 million of which were PDR (4). The pathogenesis of DR is complex, including inflammation (5), oxidative stress (6) and advanced glycation end products (AGEs) (7). Previous studies have suggested that chronic inflammation and the immune response promote the development of DR. T helper (Th) 17 cells and interleukin (IL)-17 participate in the immune response and are associated with the development and progression of DR $(8,9)$; however, this remains controversial as previous studies have demonstrated a positive association between IL-17 and DR $(8,10)$, whereas others have demonstrated a negative association (9-12).

Sirtuin 1 (SIRT1) is a nicotinamide-adenine dinucleotide $(\mathrm{NAD})^{+}$-dependent histone deacetylase associated with various fundamental physiological processes, including oxidative stress, glucose metabolism, DNA stability, aging and tumorigenesis (13-15). Previous studies have demonstrated that SIRT1 may be associated with the pathogenesis of DR $(16,17)$; however, the underlying mechanisms are yet to be elucidated. Furthermore, as previous studies have stated that SIRT1 is capable of modulating the production of IL-17 $(18,19)$, the authors of the present study hypothesized that SIRT1 functions through the regulation of IL-17 in patients with DR. In order to test this hypothesis, the present study aimed to evaluate the expression levels of SIRT1 in the retinal fibrovascular membranes and peripheral blood mononuclear cells (PBMCs) 
of patients with DR and analyze the potential association between SIRT1 expression and serum IL-17 expression levels.

\section{Materials and methods}

Patients. A total of 19 patients with PDR were recruited for the present study between April 2014 and August 2014. All of the patients had previously been diagnosed with type 2 diabetes (T2D), according to the World Health Organization (WHO) criteria (20). A total of 20 patients without diabetes who presented with idiopathic macular epiretinal membranes whilst waiting for vitrectomy were recruited as control subjects. The present study was approved by the Clinical Research Ethics Committee of the First Affiliated Hospital of Chongqing Medical University (Chongqing, China) and followed the tenets of the Declaration of Helsinki. Informed consent was acquired from all participants and detailed demographics of the patients are outlined in Table I.

Immunohistochemistry. Vitrectomy was performed on all the participants. Fibrovascular membrane samples from patients with PDR and epiretinal membrane samples from the controls were excised during the surgery, fixed in $4 \%$ paraformaldehyde, embedded in paraffin, and cut into 5- $\mu \mathrm{m}$ sections. Briefly, 10\% goat serum (Beyotime Institute of Biotechnology, Haimen, China) was used to block nonspecific binding, and the slides were incubated overnight with mouse monoclonal SIRT1 primary antibody (1:200; sc-74504; Santa Cruz Biotechnology, Inc., Dallas, TX, USA). After washing three times with Tris-buffered saline, biotinylated secondary antibody (1:150; Santa Cruz Biotechnology, Inc.) was subsequently applied for $20 \mathrm{~min}$ at room temperature and the sections were visualized using a StrepABC horseradish peroxidase kit (Beyotime Institute of Biotechnology). Subsequently, goat anti-mouse biotinylated secondary antibody (1:150; sc-2039; Santa Cruz Biotechnology, Inc.) was applied for $20 \mathrm{~min}$ at room temperature and the sections were visualized using a StrepABC horseradish peroxidase kit (Beyotime Institute of Biotechnology). SIRT1 expression levels were semiquantitatively measured using a light microscope (magnification, x200; BX51T-PHD-J11; Olympus Corporation, Tokyo, Japan), to generate an immunoreactive score (IRS) (21). Negative expression was defined by an IRS score of 0 , low expression levels were defined by an IRS score of $1-5$, whereas high expression was denoted by an IRS score of 6-12.

Circulating IL-17 measurements. Circulating expression levels of IL-17 in the sera of patients with PDR and the controls were determined using enzyme-linked immunosorbent assay (ELISA; R\&D Systems, Inc., Minneapolis, MN, USA), according to the manufacturer's protocol.

PBMC culture. PBMC culture was performed as previously described (22). Briefly, fasting blood samples were harvested from all participants using Vacutainer ${ }^{\circledR}$ tubes supplemented with heparin (BD Biosciences, Franklin Lakes, NJ, USA). PBMCs were obtained using Ficoll-Hypaque ${ }^{\mathrm{TM}}$ density gradient centrifugation (GE Healthcare, Piscataway, NJ, USA). PBMCs were cultured in RPMI-1640 medium supplemented with $10 \%$ fetal bovine serum and $1 \%$ penicillin/streptomycin (all Invitrogen, Carlsbad, CA, USA), and incubated at $37^{\circ} \mathrm{C}$ in an atmosphere containing 5\% $\mathrm{CO}_{2}$ for $24 \mathrm{~h}$. Subsequently, $1 \times 10^{6} \mathrm{PBMCs} / \mathrm{ml}$ were cultured on 24 -well plates and reverse transcription-quantitative polymerase chain reaction (RT-qPCR) or western blotting was used to determine the mRNA and protein expression levels of SIRT1, respectively. In order to ascertain the effects of an SIRT1 activator, resveratrol, on the expression levels of IL-17, anti-CD3 $(5 \mu \mathrm{g} / \mathrm{ml}$; 11-0039-41; eBioscience, Inc., San Diego, CA, USA) and anti-CD28 (1 $\mu \mathrm{g} / \mathrm{ml}$; 11-0289-41; eBioscience, Inc.) mouse monoclonal antibodies were added with/without $10 \mu \mathrm{M}$ resveratrol (Sigma-Aldrich, St. Louis, MO, USA ) (23). Resveratrol was stored as a powder and sterile phosphate-buffered saline solution (PBS) was added to the powder prior to use. Following $72 \mathrm{~h}$ incubation, the expression levels of IL-17 in the supernatants of the PBMCs were analyzed using ELISA (R\&D Systems, Inc.). The mRNA and protein expression levels of SIRT1 in the PBMCs from the patients and controls were analyzed again using the methods described below. All experiments were repeated in triplicate.

RNA extraction and RT-qPCR. An RNeasy Mini kit (Qiagen $\mathrm{GmbH}$, Hilden, Germany) was used to extract the total RNA from PBMCs, according to the manufacturer's protocol. cDNA was synthesized from $1 \mu \mathrm{g}$ total RNA using a TaqMan ${ }^{\circledR}$ Reverse Transcription kit (Applied Biosystems; Thermo Fisher Scientific, Inc., Foster City, CA, USA), according to the manufacturer's protocol. RT-qPCR was subsequently performed on an ABI 7500 Real-Time PCR system (Applied Biosystems; Thermo Fisher Scientific) using SYBR ${ }^{\circledast}$ Premix Ex Taq ${ }^{\mathrm{TM}}$ II (Takara Bio, Inc., Otsu, Japan). The following primer sequences were used: $\beta$-actin, forward 5'-GGATGCAGAAGGAGATCA CTG-3' and reverse 5'-CGATCCACACGGAGTACTTG-3'; and SIRT1, forward 5'-CGGAAACATACCTCCACCTGA-3' and reverse 5'-GAAGTCTACAGCAAGGCGAGCA-3'. The following cycling conditions were used: One cycle at $95^{\circ} \mathrm{C}$ for $3 \mathrm{~min}$, and 40 cycles of $95^{\circ} \mathrm{C}$ for $3 \mathrm{sec}$ and $58^{\circ} \mathrm{C}$ for $20 \mathrm{sec}$, followed by 1 cycle of $95^{\circ} \mathrm{C}$ for $15 \mathrm{sec}, 60^{\circ} \mathrm{C}$ for $15 \mathrm{sec}$ and $95^{\circ} \mathrm{C}$ for $15 \mathrm{sec}$. SIRT1 expression levels were normalized to the expression levels of a housekeeping gene, $\beta$-actin. Fold change was calculated using the $2^{-\Delta \Delta \mathrm{Cq}}$ method (24).

Nuclear protein extraction and western blotting. PBMCs were washed twice with ice-cold PBS and NE-PER ${ }^{\text {TM }}$ Nuclear Extraction reagents (Pierce Biotechnology, Inc., Rockford, IL, USA) were used to extract PBMC nuclear proteins, according to the manufacturer's protocol. Nuclear proteins were subsequently boiled for 10 min with $5 \%$ sodium dodecyl sulfate (SDS) loading buffer (4:1), separated by $8 \%$ SDS-polyacrylamide gel electrophoresis and transferred to a polyvinylidene difluoride (PVDF; EMD Millipore, Billerica, MA, USA) membrane. The membrane was blocked using 5\% non-fat milk and rabbit monoclonal anti-SIRT1 (1:2,000; \#2496; Cell Signaling Technology, Inc., Danvers, MA, USA) primary antibody was added to the membrane and incubated for $1 \mathrm{~h}$ at room temperature. The membrane was subsequently washed using PBS and alkaline phosphatase (ALP) buffer (Beyotime Institute of Biotechnology) containing $100 \mathrm{mmol} / \mathrm{l}$ Tris-HCl prior to incubation with ALP-conjugated secondary antibody (1:7,500; \#7054; Cell Signaling Technology, Inc., Danvers, MA, 
Table I. Characteristics of subjects.

\begin{tabular}{lccc}
\hline Characteristics & Total & Patients with PDR & Control subjects \\
\hline Number & 39 & 19 & 20 \\
Gender (male/female) & $18 / 21$ & $10 / 9$ & $8 / 12$ \\
Average age (years) & - & 59.5 & 65.8 \\
Average duration of type 2 diabetes (years) & - & 14 & - \\
\hline
\end{tabular}

PDR, proliferative diabetic retinopathy.

Table II. Sirtuin 1 (SIRT1) expression levels in samples excised from patients with proliferative diabetic retinopathy (PDR) and non-diabetic control subjects.

\begin{tabular}{|c|c|c|c|c|c|c|}
\hline \multirow[b]{2}{*}{ Sample } & \multirow[b]{2}{*}{ Case } & \multicolumn{3}{|c|}{ SIRT1 expression levels } & \multirow[b]{2}{*}{$\chi^{2}$} & \multirow[b]{2}{*}{ P-value } \\
\hline & & Negative & Low & High & & \\
\hline Fibrovascular membranes from patients with PDR & 19 & 2 & 5 & 12 & 23.85 & $<0.001$ \\
\hline Epiretinal membranes from control subjects & 20 & 16 & 3 & 1 & & \\
\hline
\end{tabular}
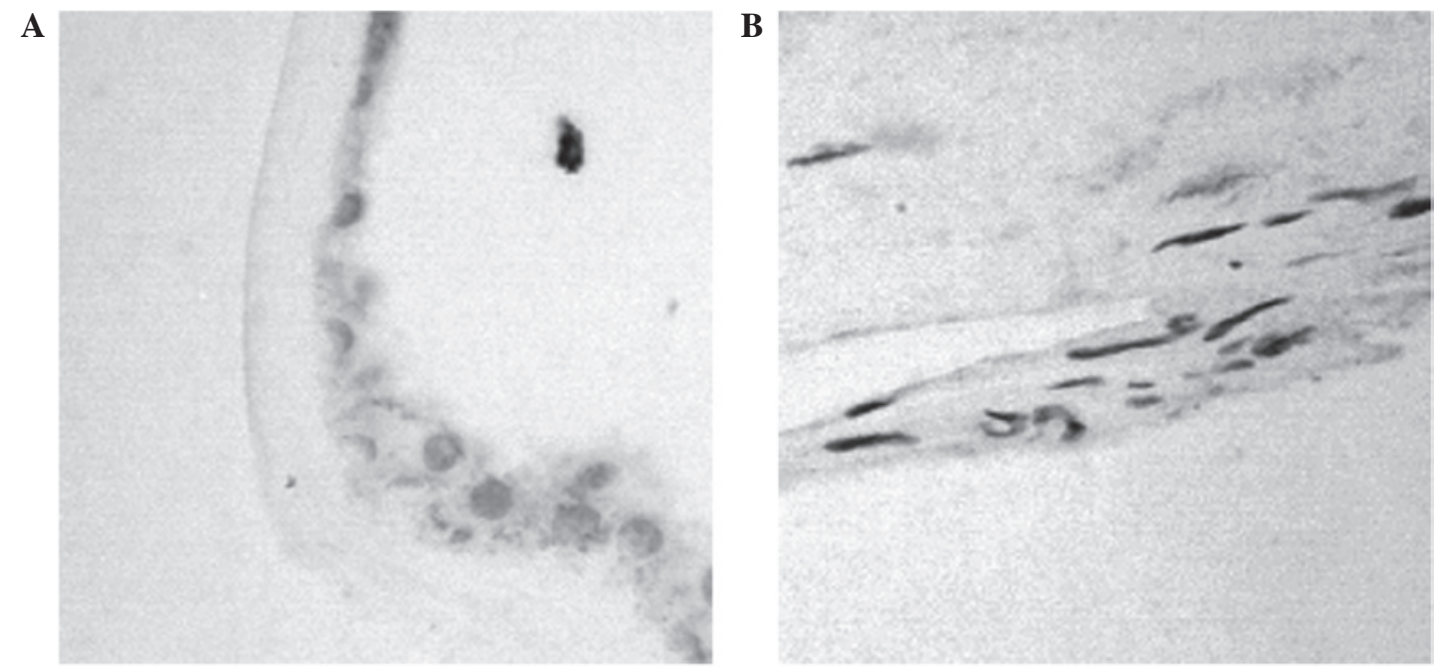

Figure 1. Sirtuin 1 (SIRT1) expression levels in the fibrovascular membranes of patients with proliferative diabetic retinopathy (PDR) and the epiretinal membranes of control subjects. (A) Positive results were detected in patients with PDR, whereas (B) the control subjects were negative for SIRT1 expression (magnification, x200).

USA) for $1 \mathrm{~h}$ at room temperature. Following this, $10 \mathrm{ml}$ ALP buffer, $66 \mu 1$ 5-bromo-4-chloro-3-indolyl phosphate (Beyotime Institute of Biotechnology) and $33 \mu 1$ nitro blue tetrazolium chloride (Beyotime Institute of Biotechnology) were mixed, added to the membrane and incubated at $37^{\circ} \mathrm{C}$. $\mathrm{ddH}_{2} \mathrm{O}$ was added once the protein bands were clear and ImageJ software, version 1.43 (National Institutes of Health, Bethesda, MA, USA) was used to quantify the protein levels. $\beta$-actin housekeeping protein was used for normalization.

Statistical analysis. One-way analysis of variance was used to compare the expression levels of IL-17 in the supernatants of the PBMCs and the mRNA and protein expression levels of SIRT1 in PBMCs. Between-group differences were determined using
Tukey's test. Student's t-test was used to compare the expression levels of IL-17 in the sera of the control and PDR groups, whereas $\chi^{2}$ test was used to compare the differences in SIRT1 expression levels in the excised membranes from the controls and patients with PDR. Statistical tests were performed using GraphPad Prism ${ }^{\circledR} 5$ (GraphPad Software, Inc., La Jolla, CA, USA) or SPSS software (SPSS, Inc., Chicago, IL, USA). Data are expressed as the mean \pm standard deviation. $\mathrm{P}<0.05$ was considered to indicate a statistically significant difference.

\section{Results}

Increased SIRT1 expression levels in fibrovascular membranes from patients with PDR. The expression levels 


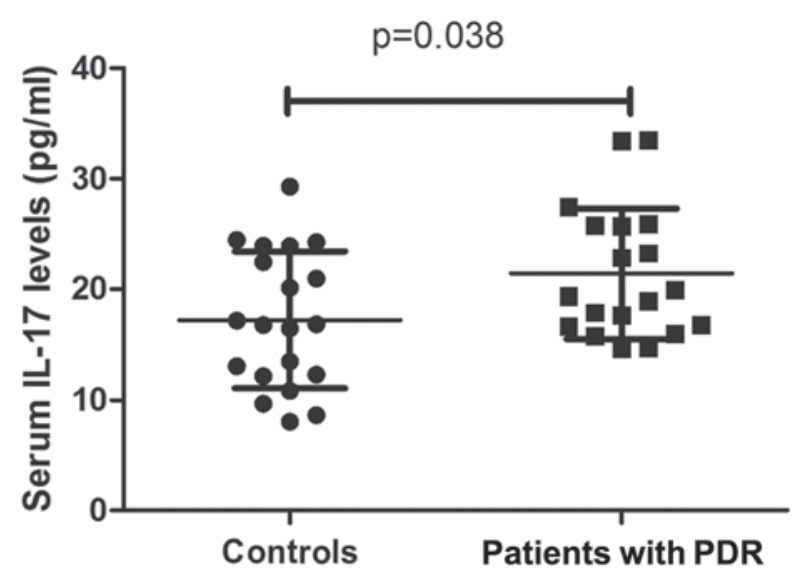

Figure 2. Interleukin (IL)-17 expression levels in the serum of patients with proliferative diabetic retinopathy (PDR; $n=19)$ and control subjects with idiopathic epiretinal membrane $(n=20)$ were assessed by enzyme-linked immunosorbent assay. Student's t-test was used for statistical analyses. $\mathrm{P}<0.05$ was considered to indicate a statistically significant difference. Data are expressed as dot plots, where the value for each patient is plotted.

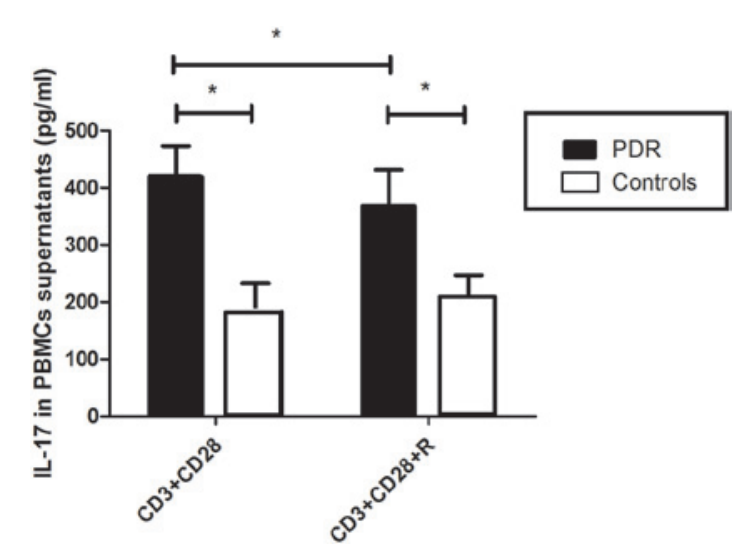

Figure 3. Interleukin (IL)-17 expression levels in peripheral blood mononuclear cells (PBMCs) from patients with proliferative diabetic retinopathy $(P D R ; n=19)$ and control subjects with idiopathic epiretinal membrane $(n=20)$ cultured with or without $10 \mu \mathrm{M}$ resveratrol (R) were examined. Statistical analysis was performed using one-way analysis of variance and Tukey's multiple comparison test was used to correct for multiple comparisons. Data are expressed as the mean \pm standard deviation. ${ }^{*} \mathrm{P}<0.05$.

of SIRT1 in fibrovascular $(n=19)$ and epiretinal membranes $(n=20)$ were examined using immunohistochemical analysis (Fig. 1; Table II). A significant difference in the expression levels of SIRT1 was demonstrated between the two groups $\left(\chi^{2}=23.85, \mathrm{P}<0.001\right)$.

IL-17 expression levels increase in the sera and PBMC supernatants of patients with PDR. IL-17 expression levels were significantly increased in the sera from patients with PDR $(21.4 \pm 5.9 \mathrm{pg} / \mathrm{ml})$, as compared with the control group (17.3 $\pm 6.2 \mathrm{pg} / \mathrm{ml} ; \mathrm{P}=0.038$; Fig. 2). Furthermore, the expression levels of IL-17 in the supernatants of cultured PBMCs were significantly increased in patients with PDR $(419.3 \pm 53.7 \mathrm{pg} / \mathrm{ml})$, as compared with the control group $(182.5 \pm 50.3 \mathrm{pg} / \mathrm{ml} ; \mathrm{P}<0.05$; Fig. 3).

SIRT1 mRNA and protein expression levels decrease in patients with PDR. The mRNA expression levels of SIRT1 in

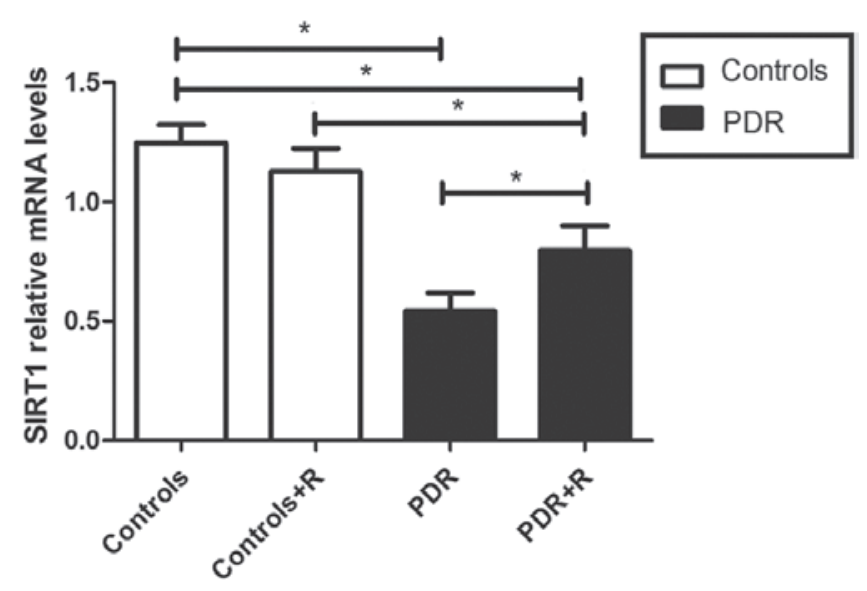

Figure 4. Relative mRNA expression levels of sirtuin (SIRT1) in peripheral blood mononuclear cells from patients with proliferative diabetic retinopathy $(\mathrm{PDR} ; \mathrm{n}=19)$ and control subjects with idiopathic epiretinal membrane $(\mathrm{n}=20)$ cultured with or without $10 \mu \mathrm{M}$ resveratrol (R) were analyzed using reverse transcription-quantitative polymerase chain reaction. Data are presented as mRNA expression levels relative to $\beta$-actin. Statistical analysis was performed using one-way analysis of variance, and Tukey's multiple comparison test was used to correct for multiple comparisons. Data are expressed the mean \pm standard deviation. ${ }^{*} \mathrm{P}<0.05$.

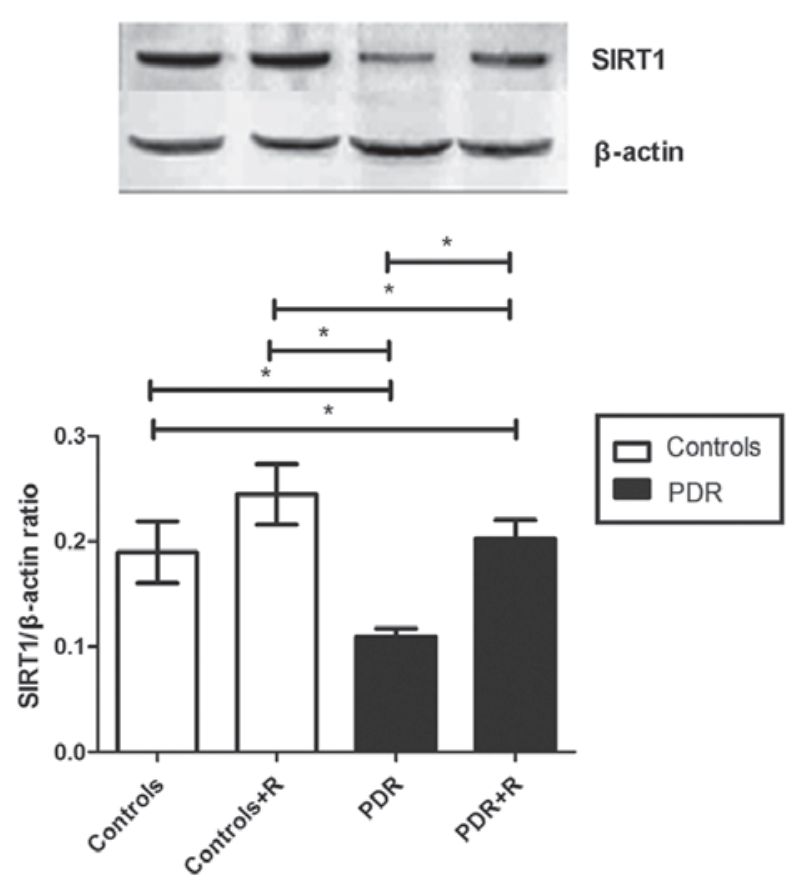

Figure 5. Protein expression levels of sirtuin 1 (SIRT1) in peripheral blood mononuclear cells from patients with proliferative diabetic retinopathy (PDR; $n=19)$ and patients with idiopathic epiretinal membrane $(n=20)$ cultured with or without resveratrol were measured by western blot. The protein bands were as follows: Control; control with $10 \mu \mathrm{M}$ resveratrol (R); PDR; and PDR with resveratrol. Statistical analysis was performed using one-way analysis of variance and Tukey's multiple comparison test was used to correct for multiple comparisons. Data are expressed as the mean \pm standard deviation. ${ }^{*} \mathrm{P}<0.05$.

the PBMCs of patients with PDR were significantly reduced, as compared with the control group $(0.54 \pm 0.08$ vs. $1.24 \pm 0.08$; $\mathrm{P}<0.05$; Fig. 4). The protein expression levels of SIRT1 were consistent with these mRNA results. In the PBMCs of patients with PDR that did not receive resveratrol 
stimulation, SIRT1 protein expression levels were significantly reduced, as compared with those from control subjects ( $0.11 \pm 0.01$ vs. $0.19 \pm 0.03$; $\mathrm{P}<0.05$; Fig. 5 ).

SIRT1 activation inhibits IL-17 production by PBMCs in patients with PDR. In order to explore the effects of resveratrol on the expression levels of IL-17 in PBMCs, PBMCs were incubated with anti-CD3, anti-CD28 and $10 \mu \mathrm{M}$ resveratrol for $72 \mathrm{~h}$, and the mRNA and protein expression levels of SIRT1 were subsequently determined. The results demonstrated that resveratrol activated the expression of SIRT1 mRNA and protein in patients with PDR (mRNA with vs. without resveratrol, $0.80 \pm 0.10$ vs. $0.54 \pm 0.08$; protein with vs. without resveratrol, $0.20 \pm 0.02$ vs. $0.11 \pm 0.01$; both $\mathrm{P}<0.05$; Figs. 4 and 5). However, SIRT1 expression levels remained lower in the PBMCs of patients with PDR following stimulation with resveratrol $(\mathrm{P}<0.05)$, as compared with those from the control group. SIRT1 expression levels in the controls were not significant affected by resveratrol administration ( $\mathrm{P}>0.05$; Figs. 4 and 5). IL-17 expression levels in the PBMC supernatants from patients with PDR were inhibited by resveratrol (with vs. without resveratrol, $368.5 \pm 62.72$ vs. $419.3 \pm 53.7 \mathrm{pg} / \mathrm{ml}$ ), and they were not altered in the control subjects (with vs. without resveratrol, $207.6 \pm 39.5$ vs. $182.5 \pm 50.3 \mathrm{pg} / \mathrm{ml}$; supernatant with vs. without resveratrol, $0.20 \pm 0.02$ vs. $0.11 \pm 0.01$; both $\mathrm{P}>0.05$; Fig. 3).

\section{Discussion}

The results of the present study indicated that serum IL-17 expression levels were increased in patients with PDR, as compared with non-diabetic control subjects with idiopathic macular epiretinal membranes. PBMCs exhibited increased expression levels of IL-17 in patients with PDR, whereas SIRT1 mRNA and protein expression levels were decreased in the PBMCs of patients with PDR. Furthermore, increased expression levels of SIRT1 were detected on the fibrovascular membranes of samples harvested from patients with PDR. These results suggested an imbalance in IL-17 and SIRT1, which may contribute to the pathogenesis of DR; therefore, SIRT1 may have protective effects in PDR.

IL-17, which is secreted by various cells including Th17 cells, is a key cytokine responsible for the recruitment, activation and migration of neutrophils. Furthermore, IL-17 is capable of inducing nonimmune cells, including endothelium and epithelium cells, to secrete proinflammatory factors (25). Previous studies have demonstrated that IL-17 has a pathological role in inflammatory and autoimmune diseases, as elevated levels of serum IL-17 have been detected in patients with diabetes (26), rheumatoid arthritis (27), psoriasis (28), multiple sclerosis (29) and systemic lupus erythematosus (30). Furthermore, IL-17 is capable of promoting angiogenesis by directly acting on endothelial cells and via other lymphokines with angiogenic properties (31). IL-17 is also capable of promoting the expression of VEGF, which is crucial in the development of PDR (32). In the present study, IL-17 expression levels were elevated in the sera and PBMCs of patients with PDR, which was consistent with previous results (11). The results of the present study also demonstrated that patients with PDR and T2D suffer from systemic inflammation, as IL-17 is capable of inducing the secretion of inflammatory factors in the endothelium, which subsequently disrupts tight junctions and the blood-retinal barrier (33); therefore, the increased expression levels of IL-17 in patients with PDR leads to retinal damage. Local expression levels of IL-17 in the vitreous fluid or retina should be investigated in future studies.

Previous studies have implicated SIRT1 in the regulation of inflammatory responses $(34,35)$, in particular, it has been demonstrated that SIRT1 is capable of modulating IL-17 production $(19,36)$; however, whether SIRT1 regulates IL-17 signaling in patients with DR remains unknown. In the present study, SIRT1 expression levels were reduced in the PBMCs of patients with PDR and, following treatment of the PBMCs with a SIRT1 activator, resveratrol, SIRT1 expression levels were upregulated. Consistent with previous studies $(18,19)$, IL-17 expression levels were inhibited by SIRT1 activation in the present study; however, in contrast with the present hypothesis that SIRT1 expression levels may be downregulated in the fibrovascular membranes of patients with PDR, SIRT1 expression was upregulated, which is consistent with the findings of Maloney et al (37). This may be due to a protective feedback mechanism in the retina; however, the precise underlying mechanism remains unclear and requires further study. Therefore, the results of present study indicated that SIRT1 may have a protective effect against DR.

There were a number of limitations to the present study. Although IL-17 and SIRT1 expression levels were compared between patients with PDR and non-diabetic controls, the associations between the two factors and the duration of PDR were not evaluated due to limitations in the number of patients. Furthermore, SIRT1 activity may reflect the function of SIRT1, however, measuring SIRT1 activity using a fluorescent SIRT1 enzymatic assay may yield artifacts and is therefore not considered to be reliable by the majority of researchers (38). As an alternative, SIRT1 mRNA and protein expression levels were measured.

In conclusion, the present study demonstrated that IL-17 expression levels were increased in the serum of patients with PDR. In addition, IL-17 expression was upregulated and SIRT1 expression levels were decreased in the PBMCs of patients with PDR. Stimulation of SIRT1 may inhibit the production of IL-17 in patients with PDR. The molecular mechanisms underlying this are complex and an improved understanding of this interplay may elucidate a new therapeutic target for the treatment of PDR.

\section{Acknowledgements}

This study was supported by National Key Clinical Specialities Construction Program of China.

\section{References}

1. Hendrick AM, Gibson MV and Kulshreshtha A: Diabetic retinopathy. Prim Care 42: 451-464, 2015.

2. Zhang X, Bao S, Lai D, Rapkins RW and Gillies MC: Intravitreal triamcinolone acetonide inhibits breakdown of the blood-retinal barrier through differential regulation of VEGF-A and its receptors in early diabetic rat retinas. Diabetes 57: 1026-1033, 2008.

3. Frank RN: Diabetic retinopathy. N Engl J Med 350: 48-58, 2004. 
4. Yau JW, Rogers SL, Kawasaki R, Lamoureux EL, Kowalski JW, Bek T, Chen SJ, Dekker JM, Fletcher A, Grauslund J, et al; Meta-Analysis for Eye Disease (META-EYE) Study Group: Global prevalence and major risk factors of diabetic retinopathy. Diabetes Care 35: 556-564, 2012.

5. Cheung CM, Vania M, Ang M, Chee SP and Li J: Comparison of aqueous humor cytokine and chemokine levels in diabetic patients with and without retinopathy. Mol Vis 18: 830-837, 2012

6. Giacco F and Brownlee M: Oxidative stress and diabetic complications. Circ Res 107: 1058-1070, 2010.

7. Milne R and Brownstein S: Advanced glycation end products and diabetic retinopathy. Amino Acids 44: 1397-1407, 2013.

8. Xu H, Cai M and Zhang X: Effect of the blockade of the IL-23-Th17-IL-17A pathway on streptozotocin-induced diabetic retinopathy in rats. Graefes Arch Clin Exp Ophthalmol 253: 1485-1492, 2015

9. Afzal N, Zaman S, Asghar A, Javed K, Shahzad F, Zafar A and Nagi AH: Negative association of serum IL-6 and IL-17 with type-II diabetes retinopathy. Iran J Immunol 11: 40-48, 2014.

10. Takeuchi M, Sato T, Tanaka A, Muraoka T, Taguchi M, Sakurai Y, Karasawa Y and Ito M: Elevated levels of cytokins associated with Th2 and Th17 cells in vitreous fluid of proliferative diabetic retinopathy patients. PLoS One 10: e0137358, 2015.

11. Nadeem A, Javaid K, Sami W, Zafar A, Jahan S, Zaman S and Nagi A: Inverse relationship of serum IL-17 with type-II diabetes retinopathy. Clin Lab 59: 1311-1317, 2013.

12. Afzal N, Zaman S, Shahzad F, Javaid K, Zafar A and Nagi AH: Immune mechanisms in type-2 diabetic retinopathy. J Pak Med Assoc 65: 159-163, 2015.

13. Longo VD and Kennedy BK: Sirtuins in aging and age-related disease. Cell 126: 257-268, 2006.

14. Li T, Zhang J, Feng J, Li Q, Wu L, Ye Q, Sun J, Lin Y, Zhang M, Huang $\mathrm{R}$, et al: Resveratrol reduces acute lung injury in a LPS-induced sepsis mouse model via activation of Sirt1. Mol Med Rep 7: 1889-1895, 2013.

15. Sung B, Chung JW, Bae HR, Choi JS, Kim CM and Kim ND Humulus japonicus extract exhibits antioxidative and anti-aging effects via modulation of the AMPK-SIRT1 pathway. Exp Ther Med 9: 1819-1826, 2015.

16. Balaiya S, Khetpal V and Chalam KV: Hypoxia initiates sirtuin1-mediated vascular endothelial growth factor activation in choroidal endothelial cells through hypoxia inducible factor- $2 \alpha$. Mol Vis 18: 114-120, 2012.

17. Zheng Z, Chen H, Li J, Li T, Zheng B, Zheng Y, Jin H, He Y, $\mathrm{Gu} \mathrm{Q}$ and $\mathrm{Xu} X$ : Sirtuin 1-mediated cellular metabolic memory of high glucose via the LKB1/AMPK/ROS pathway and therapeutic effects of metformin. Diabetes 61: 217-228, 2012.

18. Gardner PJ, Joshi L, Lee RW, Dick AD, Adamson P and Calder VL: SIRT1 activation protects against autoimmune $\mathrm{T}$ cell-driven retinal disease in mice via inhibition of IL-2/Stat5 signaling. J Autoimmun 42: 117-129, 2013.

19. Park YD, Kim YS, Jung YM, Lee SI, Lee YM, Bang JB and Kim EC: Porphyromonas gingivalis lipopolysaccharide regulates interleukin (IL)-17 and IL-23 expression via SIRT1 modulation in human periodontal ligament cells. Cytokine 60 284-293, 2012.

20. Alberti KG and Zimmet PZ: Definition, diagnosis and classification of diabetes mellitus and its complications. Part 1 : Diagnosis and classification of diabetes mellitus provisional report of a WHO consultation. Diabetic Med 15: 539-553, 1998.

21. Remmele W and Stegner HE: Recommendation for uniform definition of an immunoreactive score (IRS) for immunohistochemical estrogen receptor detection (ER-ICA) in breast cancer tissue. Der Pathologe 8: 138-140, 1987 (In German).
22. Wang C, Tian Y, Ye Z, Kijlstra A, Zhou Y and Yang P: Decreased interleukin 27 expression is associated with active uveitis in Behcet's disease. Arthritis Res Ther 16: R117, 2014.

23. Howitz KT, Bitterman KJ, Cohen HY, Lamming DW, Lavu S, Wood JG, Zipkin RE, Chung P, Kisielewski A, Zhang LL, et al: Small molecule activators of sirtuins extend Saccharomyces cerevisiae lifespan. Nature 425: 191-196, 2003.

24. Livak KJ and Schmittgen TD: Analysis of relative gene expression data using real-time quantitative PCR and the 2(-Delta Delta C(T)) Method. Methods 25: 402-408, 2001.

25. Park H, Li Z, Yang XO, Chang SH, Nurieva R, Wang YH, Wang Y, Hood L, Zhu Z, Tian Q and Dong C: A distinct lineage of CD4 T cells regulates tissue inflammation by producing interleukin 17. Nat Immunol 6: 1133-1141, 2005.

26. Sumarac-Dumanovic M, Jeremic D, Pantovic A, Janjetovic K, Stamenkovic-Pejkovic D, Cvijovic G, Stevanovic D, Micic D and Trajkovic V: Therapeutic improvement of glucoregulation in newly diagnosed type 2 diabetes patients is associated with a reduction of IL-17 levels. Immunobiology 218: 1113-1118, 2013.

27. Zizzo G, De Santis M, Bosello SL, Fedele AL, Peluso G, Gremese E, Tolusso B and Ferraccioli G: Synovial fluid-derived T helper 17 cells correlate with inflammatory activity in arthritis, irrespectively of diagnosis. Clin Immunol 138: 107-116, 2011.

28. Lynde CW, Poulin Y, Vender R, Bourcier M and Khalil S: Interleukin 17A: Toward a new understanding of psoriasis pathogenesis. J Am Acad Dermatol 71: 141-150, 2014.

29. Esendagli G, Kurne AT, Sayat G, Kilic AK, Guc D and Karabudak R: Evaluation of Th17-related cytokines and receptors in multiple sclerosis patients under interferon $\beta-1$ therapy. J Neuroimmunol 255: 81-84, 2013.

30. Wong CK, Lit LC, Tam LS, Li EK, Wong PT and Lam CW: Hyperproduction of IL-23 and IL-17 in patients with systemic lupus erythematosus: Implications for Th17-mediated inflammation in auto-immunity. Clin Immunol 127: 385-393, 2008.

31. Numasaki M, Fukushi J, Ono M, Narula SK, Zavodny PJ, Kudo T, Robbins PD, Tahara H and Lotze MT: Interleukin-17 promotes angiogenesis and tumor growth. Blood 101: 2620-2627, 2003.

32. Suryawanshi A, Veiga-Parga T, Reddy PB, Rajasagi NK and Rouse BT: IL-17A differentially regulates corneal vascular endothelial growth factor (VEGF)-A and soluble VEGF receptor 1 expression and promotes corneal angiogenesis after herpes simplex virus infection. J Immunol 188: 3434-3446, 2012.

33. Chen Y, Yang P, Li F and Kijlstra A: The effects of Th17 cytokines on the inflammatory mediator production and barrier function of ARPE-19 cells. PLoS One 6: e18139, 2011.

34. Lee SI, Min KS, Bae WJ, Lee YM, Lee SY, Lee ES and Kim EC: Role of SIRT1 in heat stress- and lipopolysaccharide-induced immune and defense gene expression in human dental pulp cells. J Endod 37: 1525-1530, 2011.

35. Kim YS,Lee YM,Park JS,Lee SK and Kim EC: SIRT1 modulates high-mobility group box 1-induced osteoclastogenic cytokines in human periodontal ligament cells. J Cell Biochem 111: 1310-1320, 2010

36. Beier UH, Wang L, Bhatti TR, Liu Y, Han R, Ge G and Hancock WW: Sirtuin-1 targeting promotes Foxp3 ${ }^{+}$T-regulatory cell function and prolongs allograft survival. Mol Cell Biol 31: 1022-1029, 2011.

37. Maloney SC, Antecka E, Granner T, Fernandes B, Lim LA, Orellana ME and Burnier MN Jr: Expression of SIRT1 in choroidal neovascular membranes. Retina 33: 862-866, 2013.

38. Pacholec M, Bleasdale JE, Chrunyk B, Cunningham D, Flynn D, Garofalo RS, Griffith D, Griffor M, Loulakis P and Pabst B: SRT1720, SRT2183, SRT1460, and resveratrol are not direct activators of SIRT1. J Biol Chem 285: 8340-8351, 2010. 